\title{
Exhaust Valve Spindles for Marine Diesel Engines Manufactured by Hot Isostatic Pressing
}

Lapina, Alberto; Hoeg, Harro Andreas; Knudsen, Jakob; Berglund, Tomas; Møller, Rune; Hattel, Jesper Henri

Published in:

Materials Research Proceedings

Link to article, DOI:

10.21741/9781644900031-14

Publication date:

2019

Document Version

Publisher's PDF, also known as Version of record

Link back to DTU Orbit

Citation (APA):

Lapina, A., Hoeg, H. A., Knudsen, J., Berglund, T., Møller, R., \& Hattel, J. H. (2019). Exhaust Valve Spindles for Marine Diesel Engines Manufactured by Hot Isostatic Pressing. In P. Dayal, \& G. Triani (Eds.), Materials Research Proceedings (Vol. 10, pp. 98-106). Materials Research Forum LLC. Materials Research Proceedings Vol. 10 https://doi.org/10.21741/9781644900031-14

\section{General rights}

Copyright and moral rights for the publications made accessible in the public portal are retained by the authors and/or other copyright owners and it is a condition of accessing publications that users recognise and abide by the legal requirements associated with these rights.

- Users may download and print one copy of any publication from the public portal for the purpose of private study or research.

- You may not further distribute the material or use it for any profit-making activity or commercial gain

- You may freely distribute the URL identifying the publication in the public portal 


\title{
Exhaust Valve Spindles for Marine Diesel Engines Manufactured by Hot Isostatic Pressing
}

\author{
Alberto Lapina ${ }^{1, a}{ }^{*}$, Harro Andreas Hoeg ${ }^{1, b}$, Jakob Knudsen ${ }^{1}$, Tomas Berglund ${ }^{2}$, \\ Rune Møller ${ }^{3}$, Jesper Henri Hattel ${ }^{3}$ \\ ${ }^{1}$ MAN Diesel \& Turbo, Teglholmsgade 41, 2450 Copenhagen, Denmark \\ ${ }^{2}$ Sandvik Powder Solutions, P.O. Box 54, SE-735 21 Surahammar Sweden \\ ${ }^{3}$ Technical University of Denmark, Department of Mechanical Engineering, Building 425, 2800 \\ Kgs. Lyngby, Denmark \\ aAlberto.Lapina@man.eu, 'Harro.Hoeg@man.eu
}

\section{Keywords: Hot Isostatic Pressing, Diesel Engine, Hot Corrosion, Nickel Alloys, Thermal} Cycling

\begin{abstract}
The exhaust valve spindle is one of the most challenging components in the marine two-stroke diesel engine. It has to withstand high mechanical loads, thermal cycling, surface temperatures beyond $700{ }^{\circ} \mathrm{C}$, and molten salt induced corrosion. Powder metallurgy gives the opportunity of improving the component using materials not applicable by welding or forging. Therefore exhaust valve spindles have been produced by Hot Isostatic Pressing (HIP) with a spindle disc coating of a Ni-Cr-Nb alloy that cannot be manufactured by welding or forging.

This paper presents the service experience gathered by MAN Diesel \& Turbo in a number of service tests on ships (up to 18000 running hours): corrosion and degradation phenomena in the spindles produced by HIP are presented and compared with the performance of state-of-the-art exhaust valve spindles.

The macroscopic geometrical changes experienced by the spindles are studied by means of Finite Element Method (FEM) calculations and strategies for further development of the component are outlined.
\end{abstract}

\section{Introduction}

The exhaust valve spindle is one of the most challenging components in the marine two-stroke diesel engine: it has to withstand high mechanical and thermal loads without benefitting from the water cooling applied to the cylinder cover and cylinder liner.

Fig. 1 shows a cross section view of the exhaust valve spindle in the closed position, i.e. when the seat area of the spindle is in contact with the bottom piece of the exhaust valve, therefore sealing the combustion chamber. The spindle bottom is directly exposed to the combustion chamber and is the hottest part of the component, with temperatures up to $600-700{ }^{\circ} \mathrm{C}$; the seat can go up to $450-500{ }^{\circ} \mathrm{C}$ instead.

During each engine cycle the spindle is heated up during the combustion step and thereafter cooled by the gases leaving the combustion chamber: therefore the spindle disc undergoes thermal cycling for each combustion cycle.

The high temperatures experienced by the spindle bottom reduce service life of the exhaust valve spindles because of "hot corrosion", i.e. corrosion due to the formation of molten salts, such as $\mathrm{Na}_{2} \mathrm{So}_{4}$ and $\mathrm{V}_{2} \mathrm{O}_{5}$, which dissolve the protective $\mathrm{Cr}_{2} \mathrm{O}_{2}$ oxide layers on the Ni-Cr alloys currently used. On the bottom of the spindle corrosion rates are usually in the range of 0.1-0.4 $\mathrm{mm} / 1000$ hours, but can soar up to $1 \mathrm{~mm} / 1000$ hours in harsh conditions. 
Currently two designs for exhaust valve spindles are available: forged Nimonic80A and Duraspindle $^{\mathrm{TM}}$. In the first the material Nimonic80A $(20 \mathrm{wt} \% \mathrm{Cr}, 2.5 \mathrm{wt} \% \mathrm{Ti}, 1.5 \mathrm{wt} \% \mathrm{Al}$, bal. $\mathrm{Ni}$ ) has excellent hot corrosion resistance and is precipitation hardened to reach sufficient hardness of the seat area. The Duraspindle ${ }^{\mathrm{TM}}$ design is a stainless steel forged substrate with welded Inconel 625 on the spindle bottom and Inconel 718 on the spindle seat. The Inconel 718 layer is cold deformed and aged to increase the hardness of the seat.

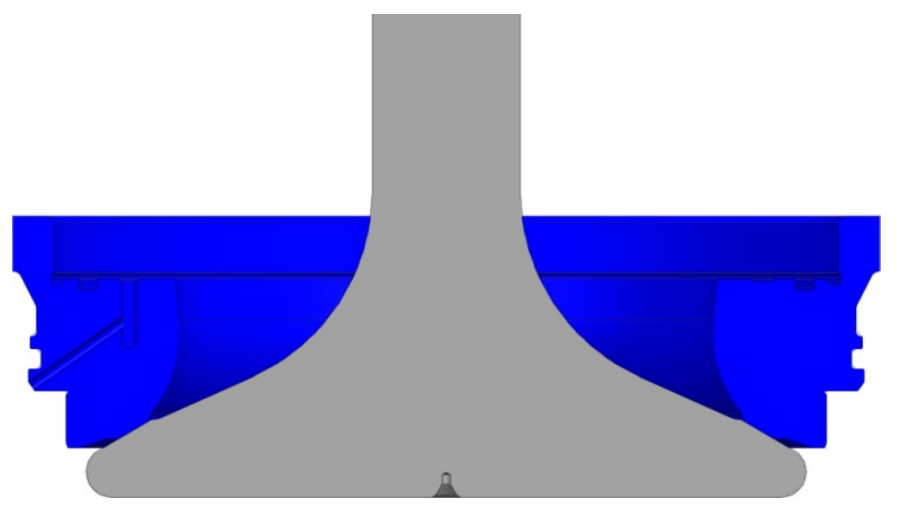

Fig. 1 Cross section of exhaust valve spindle disc (grey) and bottom piece (blue).

It was decided to test a hipped spindle because HIP allows a wider choice of materials for the spindle seat and bottom, without being limited by the forging and welding processes [1]. Moreover, it allows the flexibility of testing multiple materials at once by embedding samples in the spindle bottom [2]. This paper presents the service experience gained by MAN Diesel \& Turbo with HIP spindles and the challenges encountered.

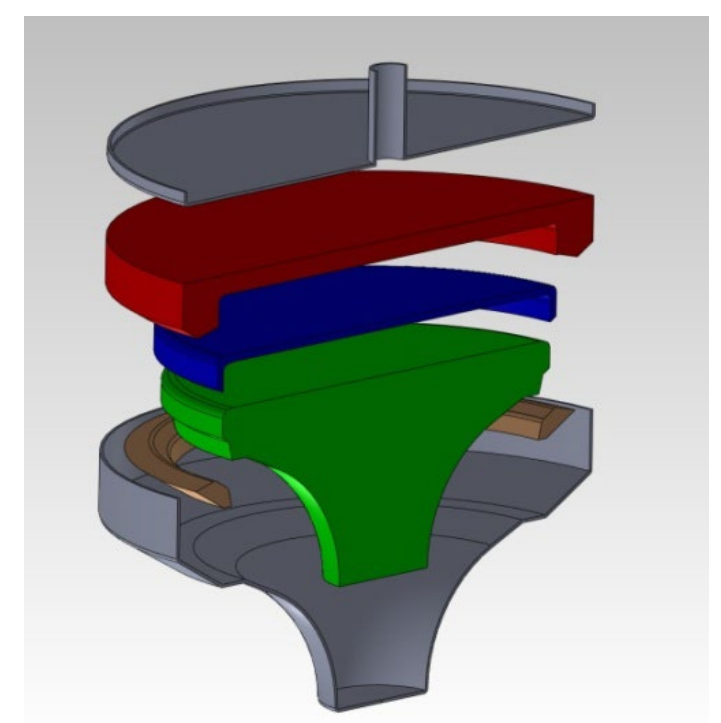

Fig. 2 The capsule design. The grey capsule parts are produced as deep drawn steel sheet being assembled by gas tungsten arc welding (GTAW). The forged disc substrate (stainless steel) is green, the seat material orange, the bottom coating (NiCr49Nb1) red and the bonding zone material (316L) blue [1] 


\section{Experimental}

Manufacturing of the spindles. the spindles were manufactured at Sandvik Powder Solutions by Hot Isostatic Pressing, according to a manufacturing procedure used for a previous test [1].

Figure 2 shows an exploded view of the spindle capsule. The substrate is the same forged stainless steel used for Duraspindle. The seat material is an experimental Ni-Cr-Nb alloy. The bottom coating is NiCr49Nb1 alloy (49\% wt Cr, 1.5 wt\% Nb, Ni bal.). A 316L buffer layer is applied between the NiCr49Nb1 bottom coating and the forged substrate to act as a diffusion barrier to prevent the formation of chromium carbides. After the hipping at $1100{ }^{\circ} \mathrm{C}$, the spindles undergo cold deformation and a precipitation hardening heat treatment to obtain high hardness in the seat area.

The spindles are then put in service on ships running on heavy fuel oil, for up to 18000 hours.

Finite element method (FEM) simulations. Because of the axial symmetry of the spindle, it is sufficient to have a 2D model of half the spindle disc (Fig. 3). The material used for the valve seat is the same as used for the spindle bottom: this will influence the stress distribution but only locally. The model consists of $\sim 260000$ three node axisymmetric linear elements with 130000 nodes. The model is analyzed using the Abaqus explicit solver. The three material layers are connected at the nodes, i.e. the layers share nodes. The model is held by constraining the nodes on the in the axial direction and the nodes on the centerline in the radial direction.

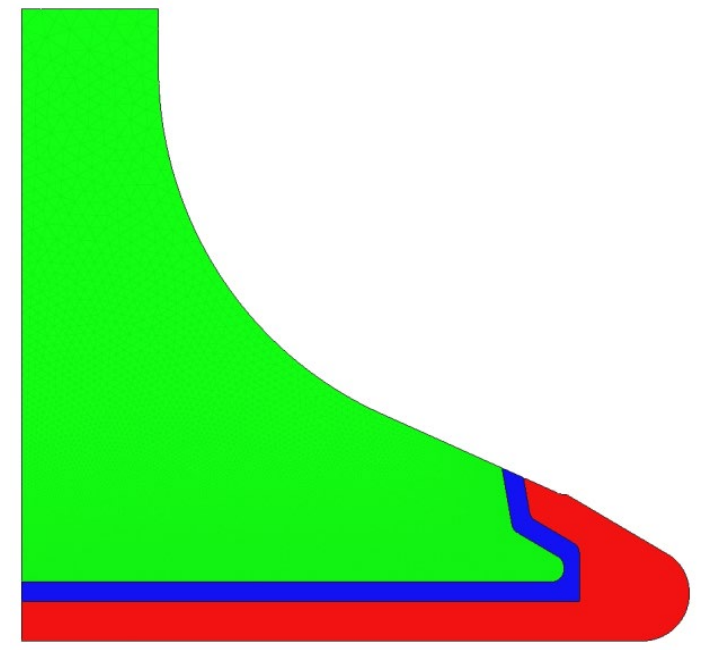

Fig. 3 FEM model of half the spindle disc.

The three materials involved are described with isotropic hardening and power law creep. The plastic material parameters are based on tensile tests of the materials whereas the creep parameters are based on literature data. An attempt to measure and apply measured creep parameters is ongoing.

The in-service mechanisms have been simplified so that the model experiences only a constant temperature field during the combustion, i.e. the entire spindle disc is uniformly heated up to $700{ }^{\circ} \mathrm{C}$, without external or internal forces applied, meaning that the occurring temperature gradient across the radius of the valve spindle is neglected. The contribution of this to the bending is considered insignificant. The temperature cycling due to the combustion cycle is not considered. 
The FEM analysis covers the HIP stage and up to five cycles of normal operation. The HIP stage involves uniform cool down from $1100^{\circ} \mathrm{C}$ to $20^{\circ} \mathrm{C}$. Each operating cycle describes heating up to $700^{\circ} \mathrm{C}$, holding for $260 \mathrm{~h}$ and then cooling to $20^{\circ} \mathrm{C}$.

\section{Results}

Corrosion rate of the bottom coating. Because of the bending of the spindle taking place during service (which is illustrated in Section "Bending of the spindle) it is not possible to measure directly the absolute value of the corrosion rate for NiCr49Nb1. However Nimonic80A and Inconel 625 samples were embedded in the bottom coating of two of the spindles during production, therefore it is possible to measure the difference in corrosion rates between these materials and NiCr49Nb1. Both materials have higher corrosion rates than NiCr49Nb1: approximately $0.07 \mathrm{~mm} / 1000$ hours for Nimonic $80 \mathrm{~A}$ and $0.15 \mathrm{~mm} / 1000$ hours for Inconel 625 .

Mechanical properties of NiCr49Nb1 and microstructure evolution. Prior to service, samples of NiCr49Nb1 have been heat treated at $700{ }^{\circ} \mathrm{C}$ for up to 4400 hours, in order to simulate the effect of service conditions on the material. Fig, 4 shows the mechanical properties of $\mathrm{NiCr} 49 \mathrm{Nb} 1$ in the as-hipped conditions and after different heat treatment times.

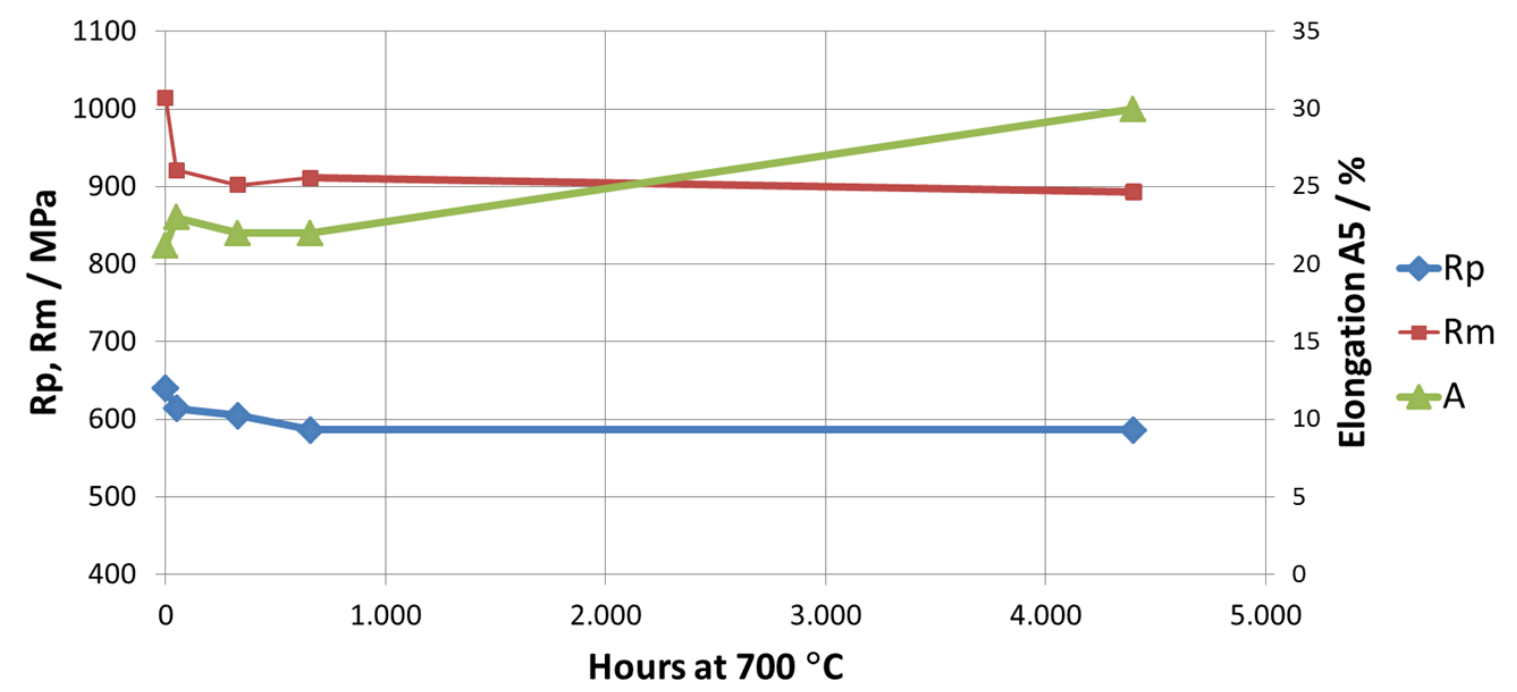

Fig. 4 Mechanical properties of NiCr49Nb1 as a function of time at $700{ }^{\circ} \mathrm{C}$.

Yield strength and tensile strength decrease significantly within the first hundred hours at 700 ${ }^{\circ} \mathrm{C}$ and then stay constant over time. Ductility instead increases significantly over a thousandsof-hours timescale.

The evolution of the material microstructure is investigated by electron microscopy: a significant change in phase distribution is seen after heat treatment at $700{ }^{\circ} \mathrm{C}$ : Fig. 5 shows backscattered electron images of as-hipped material and material after heat treatment at $700{ }^{\circ} \mathrm{C}$. The fraction of $\alpha-\mathrm{Cr}$ increases and a $\mathrm{Nb}$ rich phase (the bright phase in the electron micrographs) appears. The same has been observed in NiCr49Nb1 after service test. 

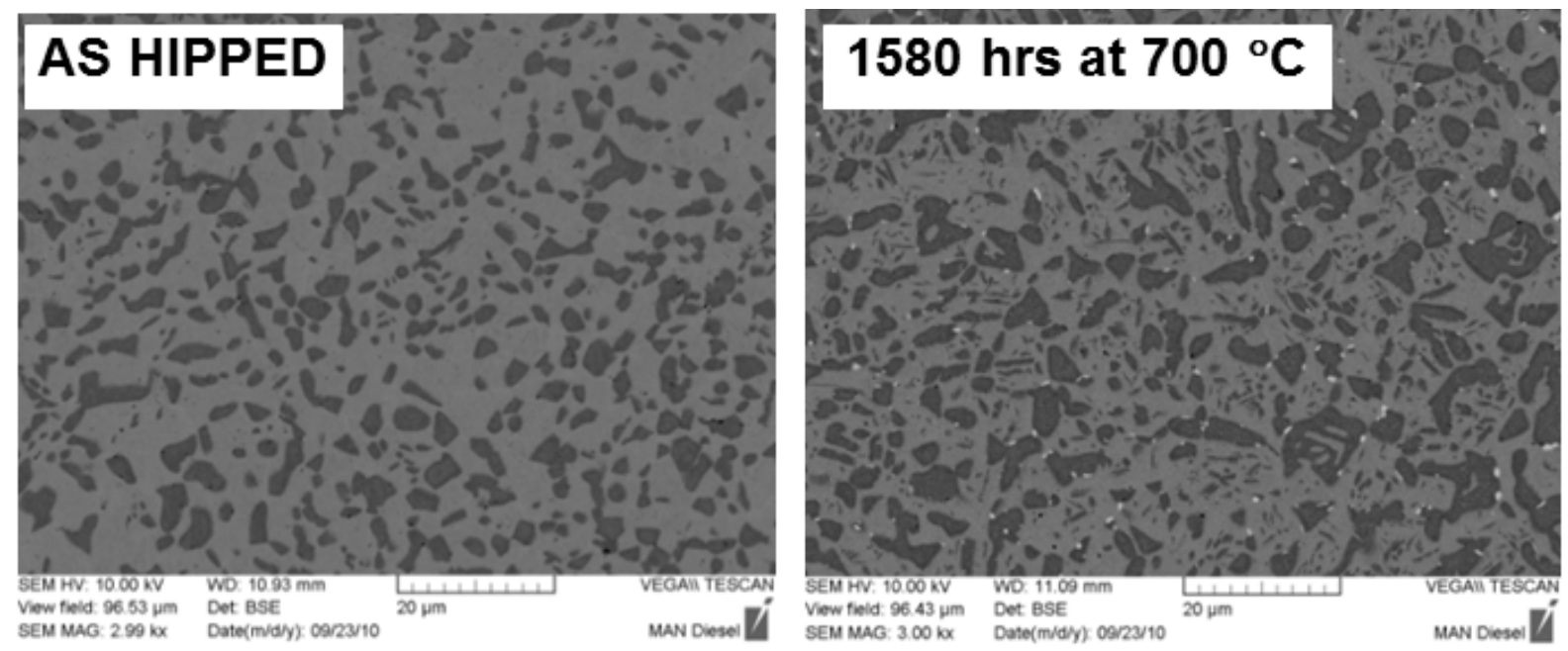

Fig. 5 Backscattered electron images of NiCr49Nb1as-hipped and after 1580 hours at $700{ }^{\circ} \mathrm{C}$.

Bending of the spindle. During service the spindle disc bends upwards, as sketched in Fig. 6. This causes the seat angle (defined as the angle between the seat surface and the direction perpendicular to the spindle stem axis, see Fig. 6) to decrease during service from the starting value of $30.3^{\circ}$ degrees.

The change in seat angle is plotted versus the service time in Fig. 7: the seat angle continues to change even after 10000 hours in service.

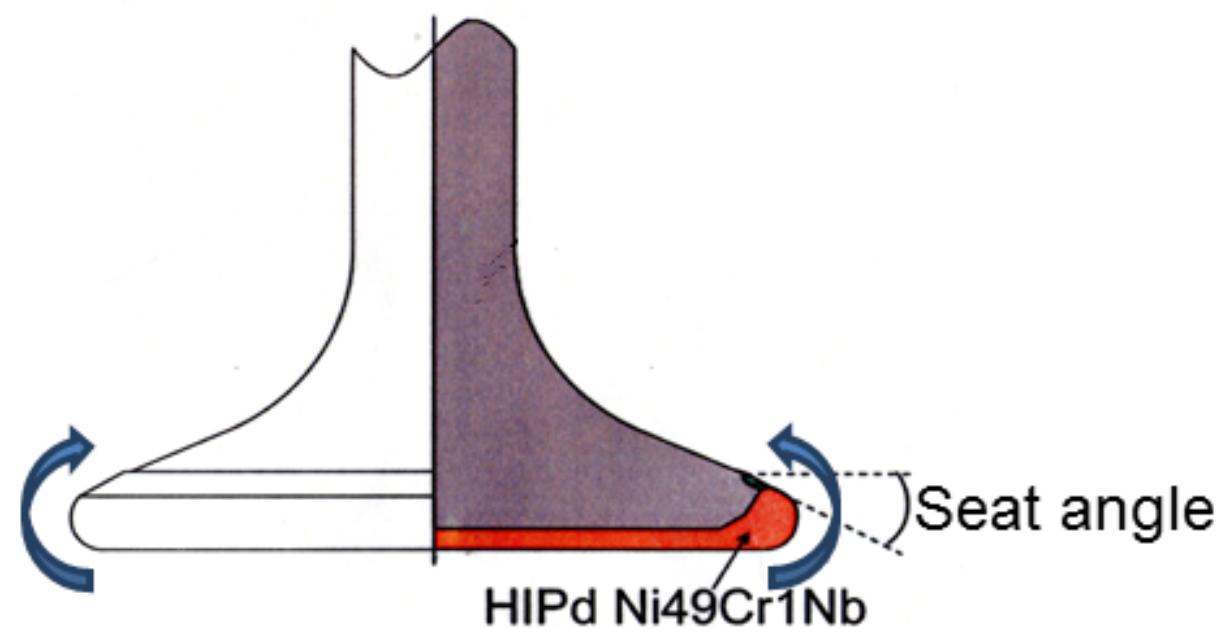

Fig. 6 Sketch of the spindle showing the seat angle and the direction of the bending.

Crack formation at the seat. Penetrant testing reveals that all the spindles, after service, have a crack running along the inner circumference of the seat area. Fig. 8 shows a polished cross section of the seat area after etching with Marble solution. The crack is perpendicular to the surface, about $3 \mathrm{~mm}$ long and crosses almost entirely the 316L buffer layer. 


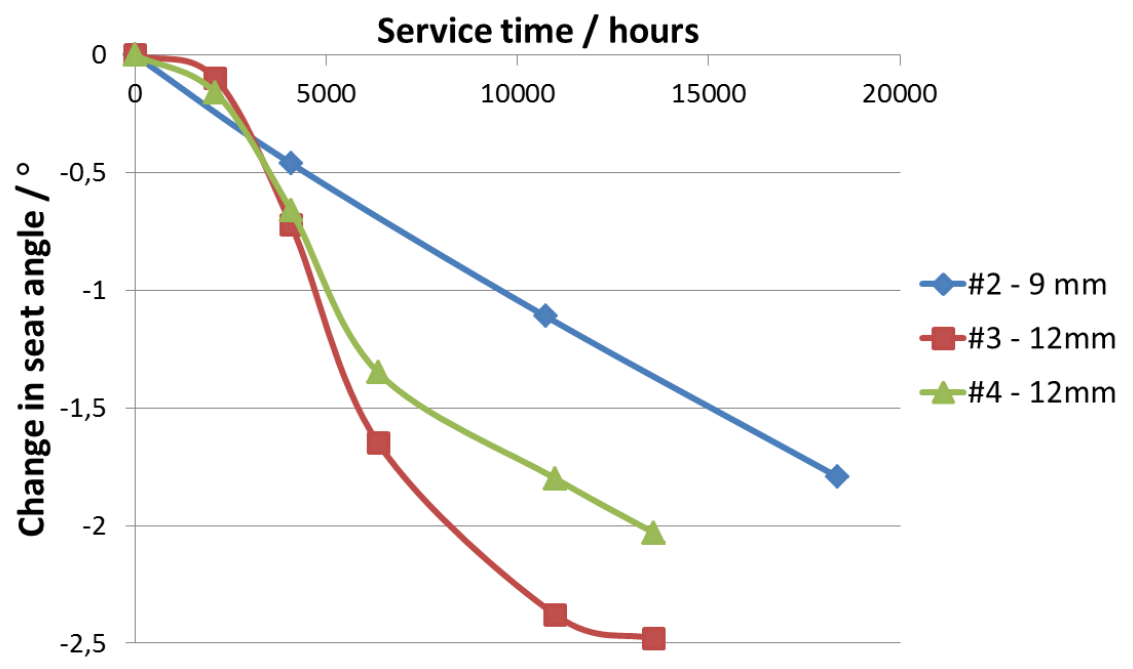

Fig. 7 Change of seat angle over service time for spindles 2, 3 and 4. "9/12 mm" refers to the thickness of the bottom NiCr49Nb1 coating.

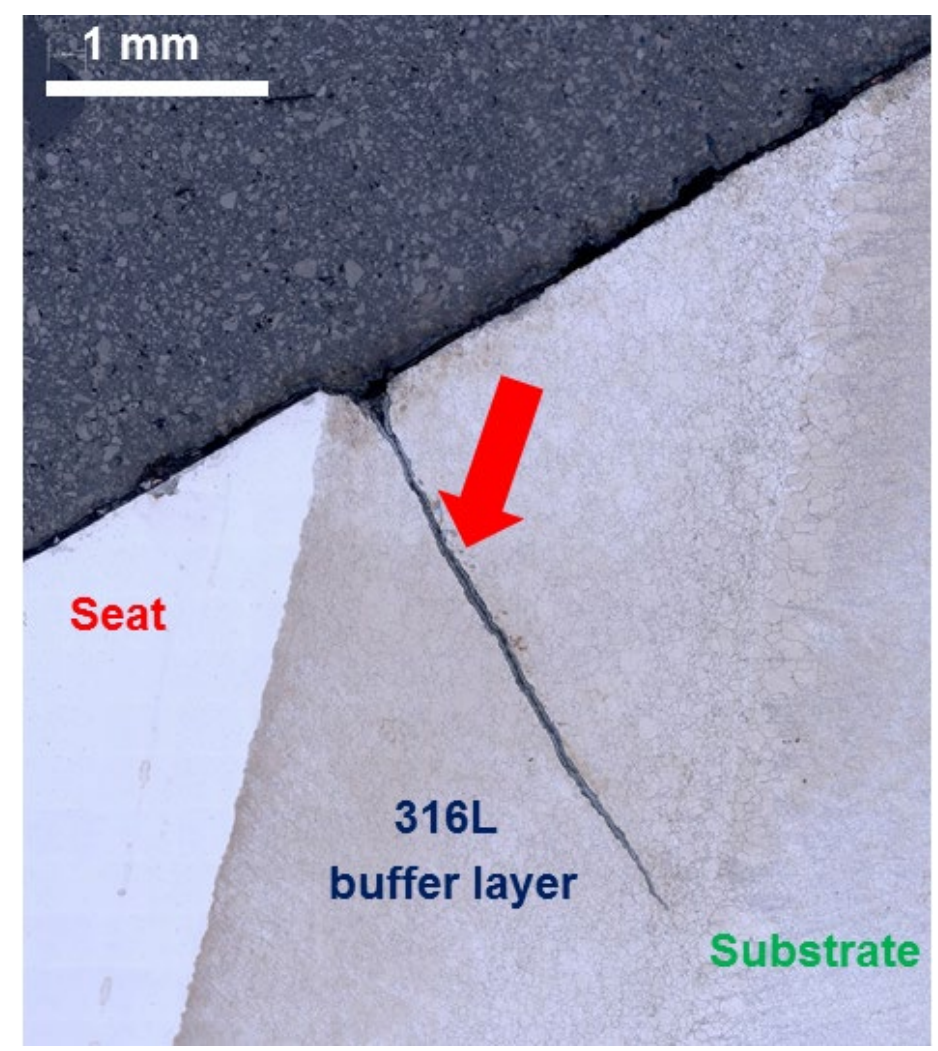

Fig. 8 Optical microscopy of cross section of the seat area after etching.

FEM calculations. Fig. 9 shows Von Mises stresses at room temperature, after the first thermal cycle and the fifth thermal cycle. Note that the resulting deformation is exaggerated/amplified to better show the bending. The von Mises stresses increase slowly with the number of cycles. The results show high stresses in the seat region and stress concentrations 
at the outward corners of the 316L layer. Concerning radial stresses, the NiCr49Nb1 coating experiences compressive stresses at the center of the spindle bottom, while the 316L layer is experiencing tensile stresses, see Fig. 10. This induces a bending moment forcing the nose upwards. Yielding is predicted to occur in the 316L layer and the seat area.

The seat angle is calculated after each of the five thermal cycles. The angle continues to decrease (i.e. the spindle bends upwards) at each cycle, reaching a change of $-0.068^{\circ}$ after 5 cycles.
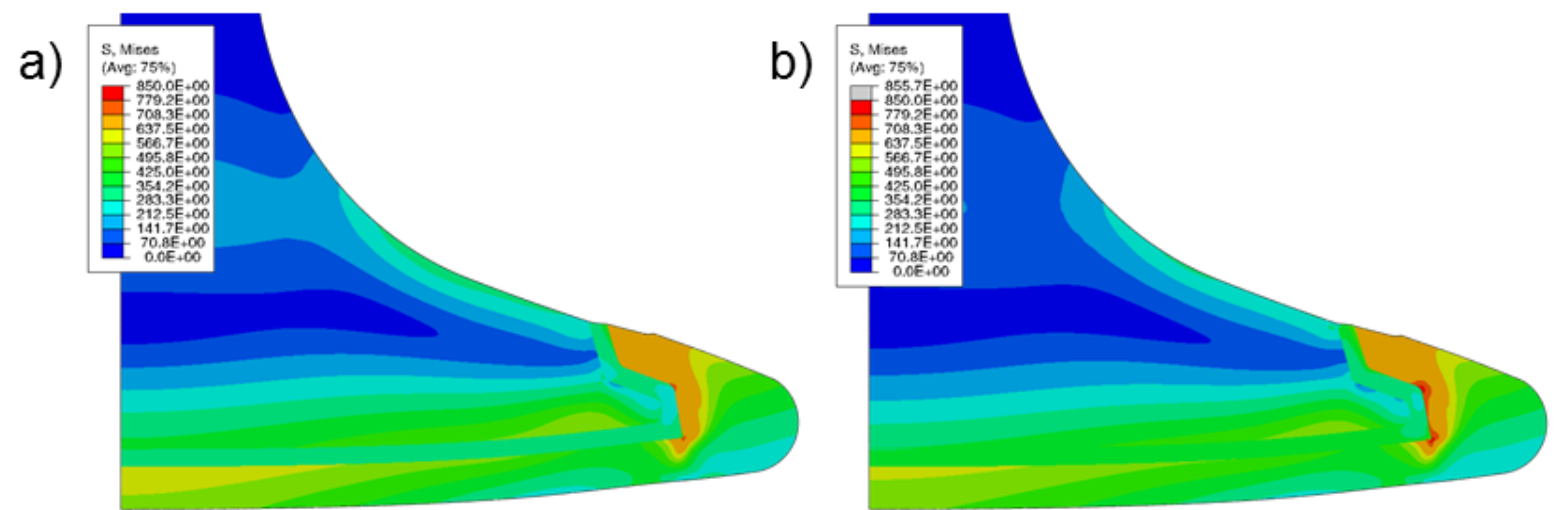

Fig. 9 Von Mises stresses after a) the $1^{\text {st }}$ and b) $5^{\text {th }}$ service cycle.

a)

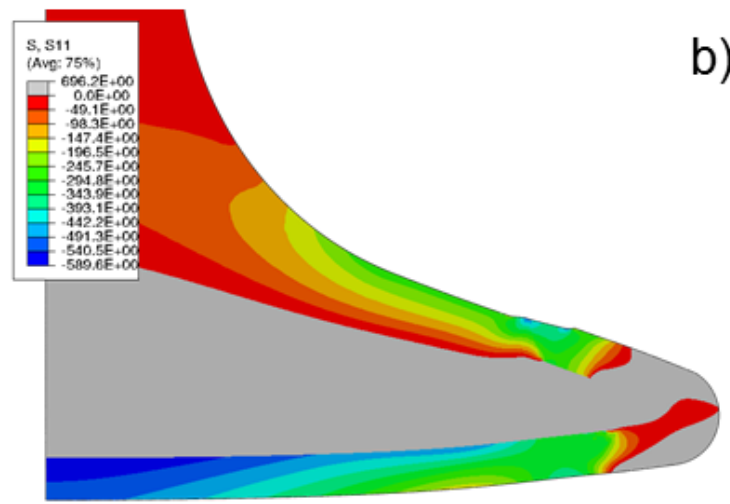

b)

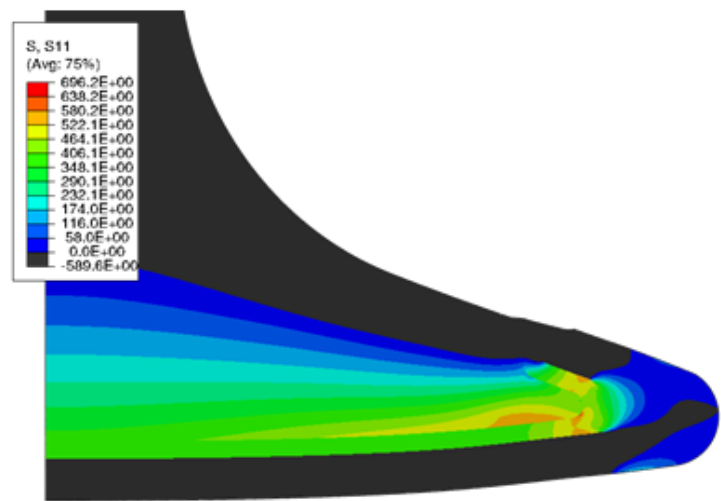

FIG. 10 a) Compressive and b) tensile radial stresses after the after the $5^{\text {th }}$ service cycle.

\section{Discussion}

Corrosion resistance. In this service test NiCr49Nb1offers only a minor improvement when compared to Nimonic80A and Inconel 625.

Previous service tests with hipped spindles on a $900 \mathrm{~mm}$ cylinder-bore engine showed instead higher differences in corrosion resistance (up to $0.3 \mathrm{~mm} / 1000$ hours for Nimonic80A and 0.57 $\mathrm{mm} / 1000$ hours for Inconel 625).

Such difference in corrosion rates between the current and previous service tests is most likely due to a higher operating temperature in the previous test. It is known that hot corrosion rates follow an Arrhenius rate law [4], thus increasing with increasing temperature.

Mechanical properties of NiCr49Nb1 and microstructure evolution. The changes in microstructure in NiCr49Nb1 can be understood on the basis of the JMatPro simulation of phase composition at equilibrium provided in Fig. 11. 


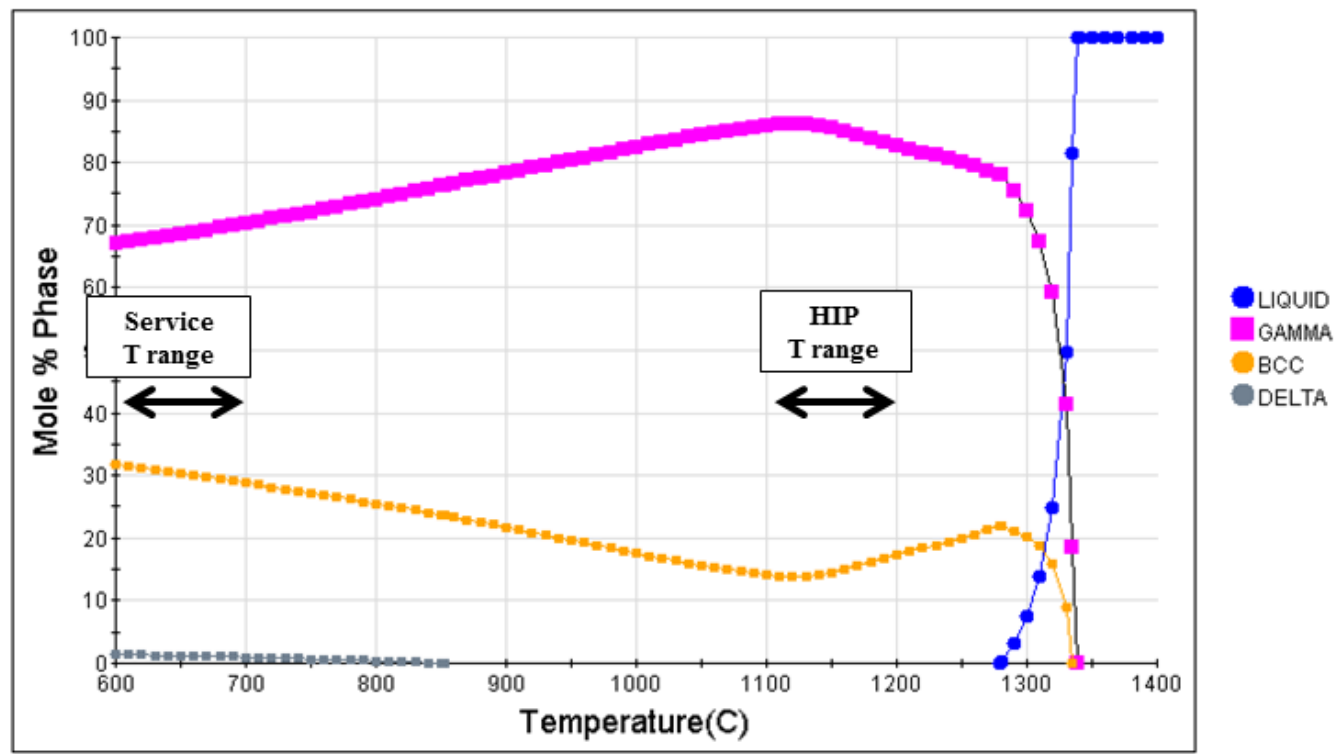

Fig 11 Simulation of phase composition of NiCr49Nb1 as a function of temperature.

There is significant difference in equilibrium phase distribution between the hipping temperature $\left(1100{ }^{\circ} \mathrm{C}\right)$ and the service temperature $\left(600-700{ }^{\circ} \mathrm{C}\right)$. A service temperature of 600 $700{ }^{\circ} \mathrm{C}$ is sufficiently high to allow diffusion processes to take place and change the phase distribution toward equilibrium conditions, increasing the fraction of $\alpha-\mathrm{Cr}$ and forming $\mathrm{Ni}_{3} \mathrm{Nb}$ particles. This behavior is observed in the material (see Fig. 5) and has been seen previously in a service test carried out on a $900 \mathrm{~mm}$ cylinder-bore engine.

The changes in microstructure are the reason for the changes in mechanical properties after heat treatment at $700{ }^{\circ} \mathrm{C}$.

Bending of the spindle and FEM calculations. During service the spindle disc deforms inelastically resulting so that the edge bends upward. This type of deformation is unique to the HIP spindle and is not observed with the current design. The root cause must therefore be found in the specific materials and processes used for the HIP spindle.

Dimensional considerations show that the deformation cannot be caused by the high-cycle thermal fatigue of the combustion cycle: the observed deflection, divided by the number of thermal cycles, would give a step value smaller than the radius of a hydrogen atom, therefore too small to be plausible.

The simulations indicate that the deformation is caused by differences in material properties of the materials involved. When the spindle heats up the base material and the 316L buffer layer expands inducing compressive stresses in the buffer layer and tensile stresses in the corrosion layer. During operation the 316L layer relaxes due to creep. When cooling down the base material and buffer layer contract inducing compressive stresses in the NiCr49Nb1 anti corrosion layer [5].

The simulation shows that the stresses in the NiCr49Nb1 coating of the seat region are so high that yielding under compression is expected. In the real spindle however, the seat material has higher yield stress than in the model. Furthermore, the simulations indicate high stress concentrations at the sharp outward corners of the 316L layer. The stress concentration is expected to be less pronounced in the real spindles since some mixing of the powders is 
unavoidable, reducing the metallurgical notch. It is not possible to model material gradients in a FEM model.

Crack at the seat. As for the bending of the spindle, the crack at the inner circumference of the seat is a damage feature unique to the HIP spindle, never observed with the current design.

The "step" (indicated by the red arrow in Fig. 8) at the seat/buffer layer interface is likely due to the different corrosion resistance of NiCr40Nb3,5 and 316L: after machining the surface is flat across the material interface, but 316L corrodes more rapidly than the seat material and so a "step" at the material interface is formed.

This step formation might likely contribute to stress concentration acting as a notch and therefore make the material in this area more prone to cracking.

Moreover, the increase in seat angle over service time means that the contact point with the bottom piece moves toward the outer part of the seat area, and this increases the momentum and therefore the stresses in the inner seat area.

\section{Conclusions and future work}

The service tests have proven that a hipped spindle with NiCr49Nb1 can operate successfully for thousands of hours. The powder metallurgy route allows using material previously not available because of welding and forging limitations.

NiCr49Nb1 has better corrosion resistance than the current state of the art materials for the spindle of bottom: the level of improvement depends on the engine and running conditions.

After an initial drop, its strength is stable over thousands of hours at service temperature.

The major challenges faced by this new design are the formation of cracks at the inner seat circumference and the bending of the spindle.

The first issue is likely caused by the second one; therefore future work will concentrate on preventing the spindle bending.

In this respect a change in the design of the buffer layer (e.g. reduced thickness, change in shape) is currently considered, and other materials are under testing.

Future simulation work will include temperature field in the spindle, and once experimental creep data for the materials involved are available, they will be implemented in the FEM model.

\section{Acknowledgments}

This development project has been supported by EUDP (Energy Technology Development and Demonstration Program), funded by the Danish government.

We thank Leonhardt \& Blumberg and Wallenius Marine for allowing service testing of the exhaust valve spindles onboard their ships.

\section{References}

[1] U.D. Bihlet, H. a Hoeg, Future HFO / GI exhaust valve spindle, in: CIMAC, Shangai, 2013.

[2] U. Bihlet, H. Hoeg, K.V. Dahl, M.A.J. Somers, In-situ hot corrosion testing of candidate materials for exhaust valve spindles, in: Int. Conf. Hot Isostatic Press., 2011.

[3] R. Møller, FE Analysis of Temperatures and Stresses In a Spindle During In-Service Conditions, 2016.

[4] J.R. Nicholls, D.J. Stephenson, Hot corrosion tests on candidate diesel valve materials, in: Diesel Engine Combust. Chamb. Mater. Heavy Fuel Oper., 1990: pp. 47-60.

[5] R. Møller, Residual stresses and in-service creep of a sintered multi-material component, Technical University of Denmark, 2014. 